


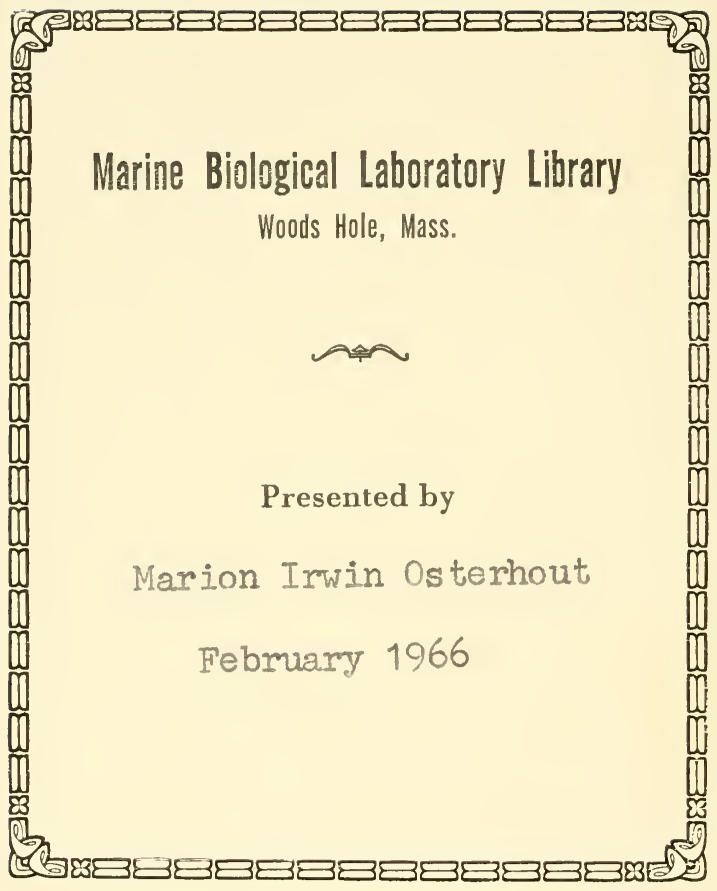




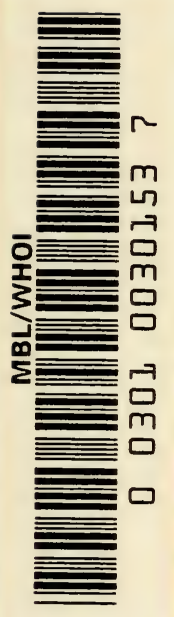



THE COLVER LECTURES IN BROWN UNIVERSITY

1922

THE NATURE OF LIFE

BY

W. J. V. OSTERHOUT 


\section{COLVER LECTURES}

HUMAN LIFE AS THE BIOLOGIST SEES IT By Vernon Kellogg THE RISE OF UNIVERSITIES

By Charles H. Haskins

THE NATURE OF LIrE

By W. J. V. Osterhout

Published by

\section{HENRY HOLT AND COMPANY}


BROWN UNIVERSITY, THE COLVER LECTURES, 1922

\title{
THE NATURE OF LIFE
}

\author{
BY \\ W. J. V. OSTERHOUT
}

PROFESSOR OF BOTANY, HARVARD UNIVERSITY
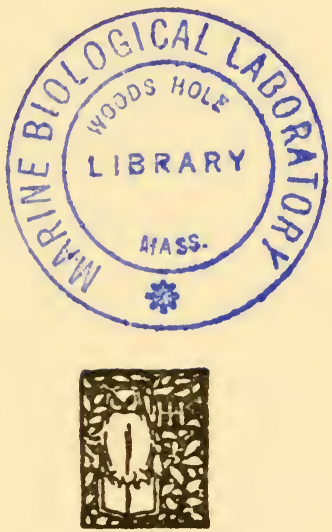

NEW YORK

HENRY HOLT AND COMPANY 


\section{Coprright, 1924 \\ BY \\ BROWN UNIVERSITY}

PRINTED IN THE

UNITED STATES OF AMERICA 
The Colver lectureship is provided by a fund of $\$ 10,000$ presented to Brown University by Mr. and Mrs. Jesse L. Rosenberger of Chicago in memory of Mrs. Rosenberger's father, Charles $\mathrm{K}$. Colver of the class of 1842. The following sentences from the letter accompanying the gift explain the purposes of the foundation:

"It is desired that, so far as possible, for these lectures only subjects of particular importance and lecturers eminent in scholarship or of other marked qualifications shall be chosen. It is desired that the lectures shall be distinctive and valuable contributions to human knowledge, known for their quality rather than their number. Income, or portions of income, not used for lectures may be used for the publication of any of the lectures deemed desirable to be so published."

Charles Kendrick Colver (1821-1896) was a graduate of Brown University of the class of 1842. The necrologist of the University wrote of him: "He was distinguished for his broad and accurate scholarship, his unswerving personal integrity, championship of truth, and obedience to God in his daily life. He was severely simple and unworldly in character."

The lectures now published in this series are:-

1916

The American Conception of Liberty and Government, by Frank Johnson Goodnow, LL.D., President of Johns Hopkins University.

\section{7}

Medical Research and Human Welfare, by W. W. Keen, M.D., LL.D. (Brown), Emeritus Professor of Surgery, Jefferson Medical College, Philadelphia. 
The Responsible State; A Reëxamination of Fundamental Political Doctrines in the Light of World War and the Menace of Anarchism, by Franklin Henry Giddings, LL.D., Professor of Sociology and the History of Civilization in Columbia University; sometime Professor of Political Science in Bryn Mawr College.

\section{9}

Democracy: Discipline: Peace, by William RosCOE ThaYer.

1920

Plymouth and the Pilgrims, by ARthur LoRd.

1921

Human Life as the Biologist Sees It, by Vernon KeLLoGg, Sc.D., LL.D., Secretary, National Research Council; sometime Professor in Stanford University.

\section{2}

The Nature of Life, by W. J. V. Osterhout, Professor of Botany, Harvard University.

\section{3}

The Rise of Universities, by Charles H. Haskins, Ph.D., LL.D., Litt.D., Gurney Professor of History and Political Science, in Harvard University. 


\section{CONTENTS}

PAGE

I. The Origin of Life a . . . 3

II. GRowth

III. Reproduction $\quad \cdot \quad \cdot \quad \cdot \quad \cdot \quad \cdot \quad \cdot \quad 22$

IV. Motion $\quad . \quad$. . . . . . . $\quad 29$

V. IrRitability

VI. Metabolism . . . . . . . . 45

VII. Selective Permeability a . . 74

VIII. Electrical Forces . . . . . 84

IX. The Control of Life a . . . 88

INDEX * . . . . . . . . 111 



\section{THE NATURE 0F LIFE}





\section{THE NATURE OF LIFE}

\section{I \\ THE ORIGIN OF LIFE}

At the present time astronomers present a picture of the evolution of the universe which holds the imagination captive. Some of them believe that all kinds of matter have been evolved from one original substance, hydrogen, and that out of the material thus created solar systems were built up. They are able to give us a fairly satisfactory description of the processes which formed bodies like our earth. Their account is supplemented by the geologist, who pictures the progressive changes on the surface of the earth whereby it became fitted to support life. The fascination of these researches is heightened when we consider that they lead directly to a question of universal interest which lies in the province of the 
biologist, How did life make its appearance on our planet?

To this question an answer was given long ago by Lucretius and others, who said that life arose out of lifeless materials. This is known as the doctrine of spontaneous generation.

The adherents of this doctrine believed that life could arise from nonliving materials whenever the conditions were favorable. For a long time this belief found favor with many thinkers. But the experiments of Pasteur and Tyndall showed that if all the living organisms in a nutrient solution were killed, and if it were kept free from contamination by germs from without, no life subsequently appeared.

In spite of this evidence the doctrine of spontaneous generation was revived from time to time. One of the ablest botanists of the past generation predicted that we should one day discover living forms too small to be seen by our microscopes; these, he said, represent 
the earlier steps in the evolution of living forms from lifeless matter. This prediction has been verified in so far as we now know a considerable number of such forms (filterable viruses) some of which cause important diseases. They can not be detected by the ordinary microscope; they pass through filters which retain all the ordinary bacteria. But we do not think of them as lending support to the doctrine of spontaneous generation, since there is no proof that they can arise from lifeless material.

How then did life originate? Are we not forced to assume that somewhere, at some time, spontaneous generation must have taken place? Although no such process appears to occur at present we may nevertheless suppose that in earlier geological epochs and under more favorable conditions it might have happened. And if, as Arrhenius supposes, life can originate on any appropriate heavenly body and spread thence to other bodies we have an immense extent 
of time and space in which to find conditions favorable to the origin of life. It may be that such conditions have never existed on our planet and perhaps have occurred but rarely in the history of the universe. It is not impossible, however, that we may learn of their occurrence, in the past or the present, since the spectroscope gives us accurate information about the composition of heavenly bodies and, in the case of distant stars, tells us what they were like thousands of years ago. If we do not observe on the earth the conditions necessary for the origin of life we may perhaps hope to find them in some of these heavenly bodies which might differ sufficiently from our planet to provide the necessary combination of factors.

Arrhenius thinks that spores of bacteria might be carried to the upper limits of our atmosphere and thence be expelled into interstellar space, poetically called the "ether sea." There the spores might be driven away from the sun by the action 
of light, which might exert on such small bodies pressure sufficient to carry them to the outermost limits of our solar system. Thus interstellar space might conceivably be peopled with spores which could come in contact with any heavenly body that had reached a stage in its development at which life could be supported.

It has been objected that the spores might be killed by intense cold, dryness, lack of air, or the action of light. But some spores are resistant to these influences and it is by no means certain that they could not survive a long time in interstellar space.

The theory of Arrhenius stands out as a stimulating example of speculative thought. It is inspiring to picture life, taking flight from worlds outworn to fresh fields in younger planets, and persisting as long as the universe can harbor it, in cycle on cycle of endless progress. We may admire this beautiful theory as a splendid achievement of the creative 
8 THE NATURE OF LIFE

imagination but we cannot at present prove or disprove its correctness. If it should one day turn out to be true it will greatly widen the possibility of finding appropriate conditions for the origin of life.

\section{II \\ GROWTH}

LEAving this riddle of the origin of life, let us turn to another question of equal importance. What new factor entered into the universe with the first appearance of life? We may perhaps put this in a more concrete form by asking, How may we distinguish the living from the dead?

It may not seem very difficult to answer this question but the matter is less simple than might at first appear. As an illustration let us take some dry seeds. Their appearance does not tell us whether they are alive or dead. Most people if called upon to decide would 
plant them, and use growth as a test of life.

If we are to employ growth in this manner it is important to have a clear understanding of what it means. Growth is often thought of as comprising the whole development of the organism. Ordinarily the life cycle of an animal or plant begins with a single cell, which by repeated division produces a mass of cells. The form of the organism then changes, and its parts become differentiated so as to perform different functions.

The question now arises, What is essential to the conception of growth? A simple illustration will make it clear that growth may go on without cell division, change of form or color, differentiation, or assimilation of food. A small, spherical, green cell, desiccated by the drying up of a pool in which it has lived, and blown about by the wind, eventually falls into water. Such a cell often remains alive and when it again finds it- 
self in water begins to grow. No one will deny that this is genuine growth but it certainly need not possess all the features which we have enumerated. In the first place cell division may be absent for a long time. Many cells increase enormously in size and never undergo division. A nerve cell may grow to be many hundred times its original length without dividing; and it will continue to function for years and finally die without any sign of nuclear or cell division. We cannot therefore regard cell division as essential to the conception of growth, though in most cases it accompanies growth and is advantageous because it provides separate compartments in which the diverse processes of the organism can go on without mutual interference.

There may be no change of form or color in the green cell of which we are speaking, since it may remain green and spherical while growing. Nor is there any reason to suppose that in general a change of form is essential to growth. 
It commonly occurs but is by no means indispensable. Nor is it necessary that a differentiation of the organism into unlike parts should take place in order that a process may be called growth. Such differentiation is not observed during the growth of the simplest cells, such as bacteria, which may have at the beginning all the parts they possess when growth is complete.

Of especial interest is the assimilation of food and the building up of those substances which are characteristic of each kind of organism. We know that seeds can grow for weeks in the dark, absorbing nothing except air and water. Under these circumstances the food which is stored in the seed steadily decreases. A kidney bean grown under such conditions may reach a height of four feet and gain in weight more than fifty fold. Yet this great gain in weight is wholly due to the water it absorbs. Its dry matter steadily decreases during the whole period, undergoing a process of combustion 
which results in continually giving off carbon dioxide to the air. In this way nearly half the dry material may disappear during growth.

It is true that growth must eventually cease under these circumstances but the fact that it can go on for so long although the plant takes in no food shows that increase in dry weight is not necessary for growth.

Since we find that growth may occur without increase in dry weight, change of form or color, cell division, or differentiation, we may ask, What is really essential to growth? The answer seems to be, An increase in size due to the absorption of water. Let us now look into this more closely.

It is a very striking fact that when dry seeds are planted in moist soil the dead seeds appear to grow in the same way as the live ones during the first few hours. We find, however, that a dead seed soon stops growing while the living one continues. This suggests that the 
water is not absorbed in quite the same manner in the two cases. Absorption of water may occur in two ways, which are known as imbibition and osmosis. Imbibition is the process which occurs when a piece of dry wood is placed in water. The water is taken up into minute pores, other processes follow, and the result is a swelling which, though short-lived, can develop great pressure. At one time granite blocks were split open by drilling holes in a straight line and inserting plugs of dry wood. These were covered with wet rags, the wood absorbed water and the granite block was split. Careful measurements show that starch may develop a pressure of thirty thousand pounds per square inch in taking up water. It is therefore no wonder that a ship loaded with rice is quickly burst asunder if water reaches the cargo.

In osmosis water is absorbed in a different way. This may be illustrated by the story of the good abbé who hid a 
skin of wine in the cistern of the abbey. When the monk developed an unusual taste for water he investigated and found to his horror that the skin had burst. The wine had taken up water through the skin because it contained substances which attract water (the word "attract" is here used in a somewhat figurative sense). In the living cell there is a protoplasmic membrane which corresponds to the skin, and inside this a solution which attracts water. As water is taken up the protoplasmic membrane is stretched, and if there is a cellulose wall outside the living membrane it shares the same fate. The living membrane can be stretched almost indefinitely because the cell can furnish it with new material so that it can continue to expand without rupture. At the same time the cell can produce substances which attract water. It is therefore possible for growth to continue indefinitely.

The growth of the dead seed is due to imbibition while that of the living seed is 
due during the first few hours principally to imbibition, after that principally to osmosis. We should therefore expect that the dead seed would soon stop growing while the living one would continue.

Osmosis does not ordinarily develop so much pressure as imbibition but it is supposed that the pressure it produces in the living cell may reach three hundred pounds per square inch or even more: this is as much as is commonly found in steam boilers. It is sufficient to drive ferns up through macadamized roads and concrete sidewalks and to enable toadstools to lift heavy flagstones.

Let us now consider whether there is anything in growth which can be used as a criterion of life. We have tried first of all to discover what is essential to growth. Such things as cell division, change of form, differentiation, and the assimilation of food may be taken away, and yet growth may go on for a long time. One process cannot be dispensed 


\section{THE NATURE OF LIFE}

with, the absorption of water. This appears to be the essential thing.

If growth consists of the absorption of water can this serve as a test to distinguish the living from the dead? As we have seen, absorption of water takes place by imbibition or by osmosis. Imbibition cannot serve as a mark of distinction for it goes on in the same way in dead and in living seeds. If we are to employ growth as a test of life it can be only on the ground that osmosis is in some way peculiarly characteristic of living cells. Let us see whether this is the case.

One way of attacking this question is to attempt to make an artificial cell which will act like the living. We may employ for this purpose two solutions, $A$ and $B$, such that a drop of $A$ introduced into a vessel containing $B$ will react with it and form a membrane which is impervious to both $A$ and $B$, but is permeable to water. We have now what we may for convenience call an ar- 
tificial cell. It consists of a membrane in the form of a rounded sack which completely incloses a drop of the solution $A$ and which is surrounded by the solution $B$. If now solution $A$ is more concentrated than solution $B$ water will be attracted by solution $A$ and will pass into the artificial cell which in consequence will expand and stretch the membrane. Under the proper experimental conditions this may continue for a long time.

We may employ for such experiments a great variety of materials, as copper salts in a solution of potassium ferrocyanide, metallic salts of various kinds in a solution of water glass, or tannic acid in a solution of gelatin. In some cases the artificial membrane expands by repeated rupture and repair, in others it is steadily stretched without rupture, and at the same time strengthened by the deposit of new material. The protoplasmic membrane might conceivably expand in either way. It is not certain which method is followed. 


\section{THE NATURE OF LIFE}

In both the living and the artificial cell growth is quickened by increase of temperature. In the living cell there is an upper limit of temperature beyond which no growth takes place. This seems to be due to the proteins of the living cell. If we could employ such proteins in the membrane of the artificial cell we might obtain a similar result.

The rate of growth depends, in the living as in the artificial cell on the supply of substances within the membrane which can attract water. In the case of the living cell these are mostly sugars, organic acids, salts, and so on, and we can employ these same substances in the artificial cell. In the living cell we often find starch, which takes little part in attracting water but which may be gradually transformed into sugar which attracts water actively. In the same way we may place starch in the artificial cell and have it slowly transformed to sugar and thereby cause the cell to take up water. 
If the artificial cell is placed in a solution which is more concentrated than that inside the cell, water is attracted from the cell to the outside solution and in consequence the cell shrinks. This is also true of the living cell. If it is growing in tap water it can be made to shrink by putting it into a sugar solution which withdraws water. If replaced in water it again expands. Since we regard this as growth, the shrinkage may be looked upon as the reversal of growth. We find that many living cells may be made to grow and shrink several times in succession, just as in the case of the artificial cell.

If the outside solution is concentrated enough to draw water out of the cell it may nevertheless prevent water from going in and so check growth in proportion to its concentration. Consequently by varying the concentration we may accurately control the rate of growth.

We might go on to discuss other points of resemblance between the growth of 
the living and the artificial cell but this hardly seems necessary. If we accept the definition of growth given above it is clear that the artificial cell furnishes an imitation which is sufficiently complete for our purpose. We must therefore conclude that there is nothing in the absorption of water by the living cell, either by imbibition or by osmosis, which differs essentially from these processes as found in non-living systems.

In conclusion we may ask whether life can go on in the absence of growth. We know that certain things may be temporarily taken away from living matter without taking away life itself. Is growth one of these? Certainly the resting seed lives for years without any sign of growth. This is also true of many animal cells. The suppression of all signs of growth does not in any way involve the suppression of life. Even when placed in moist soil with all external conditions favorable some living seeds re- 
main quiescent for months or years before they start to grow.

Hence it seems possible to have life without growth and growth without life.

Our analysis of the process of growth illustrates the method which biological investigation must very commonly pursue. The biologist wishes to study living matter in the same manner that the chemist and physicist study their material. His first task is observation, after that he must analyze in order to discover what properties are essential and what are merely accompanying phenomena. He need not attempt to explain these phenomena, for, after all, we can never arrive at ultimate explanations. But he can attempt to predict and control. The physicist cannot explain electricity but he can predict and control electrical phenomena. In the same way the biologist hopes to be able to predict, and control life phenomena. One method which he finds particularly useful is to make artificial imitations which closely resemble 
the phenomena he is studying. If he succeeds in this he may find the fundamental laws of physics and chemistry on which life phenomena are based.

\section{III}

\section{REPRODUCTION}

Since we cannot regard growth, as already defined, as an adequate means of distinguishing the living from the nonliving we may try to find a better criterion. Let us now consider reproduction from this point of view.

Reproduction consists essentially in setting free from the organism a portion which continues to grow and which ordinarily reproduces in its turn.

In some cases the detachment is due to the action of wind, waves, or other external forces. Thus there are certain plants each of which consists of a single large cell (containing many nuclei) which may be ruptured by purely mechanical 
means so that a portion becomes detached. The protoplasmic membrane at the surface of the cell (which has been mentioned above) is broken by the act of detachment but it is at once repaired in both parts of the cell so that each portion is able to continue its growth.

This may also happen in the artificial cell described above. Here also the membrane is instantly repaired when the cell is ruptured and both portions continue to grow. The rupture and repair of the membrane, therefore, do not serve to distinguish the living from the nonliving.

The rupture of the living cell, as previously described, produces two portions which are similar except in size and each constitutes a complete individual. An analogous case (in respect to individual completeness) is found in the strawberry plant, which produces runners. If one of these runners becomes detached by mechanical means, or by the decay of the connection between it and the mother 


\section{THE NATURE OF LIFE}

plant, it constitutes a complete new individual.

In some cases the detached portion is incomplete, as when a willow branch is broken off by the wind, falls into soft mud and begins to grow. It must produce roots in order to become a complete individual. This process of completing the individual is known as regeneration. It is of common occurrence, but, as we have seen, it is absent in the simplest cases and is therefore not essential to the idea of reproduction.

The detachment of a portion of the organism is often brought about by internal forces as seen in the process of cell division by which a cell separates itself spontaneously from the parent organism.

In the simplest cells, where there is no definite nucleus, the process of cell division may consist in a simple constriction which cuts the cell in two. This process may be imitated in drops of oil and seems to be due primarily to the forces which act at the surface of every liquid. Under 
the action of these forces a drop of liquid rounds up and becomes spherical whenever it is free to do so. But when these forces are disturbed by localized chemical action they may cause a constriction of the drop which may result in its division into two parts. The same forces seem to operate in the case of the cell and in addition there may be changes in the consistency of the protoplasm. There seems, therefore, to be nothing in such cases which we may not hope to explain on a physicochemical basis.

For the more complicated cases, where division of the nucleus occurs, we have at present no satisfactory explanation. We need not, however, concern ourselves with these cases at present, since our purpose is to reduce each life process to its simplest form and try to see whether we can explain it on a physicochemical basis. If we succeed in this we may be content to leave the more complicated cases to future investigation.

In sexual reproduction there is a fusion 
26

of two cells called gametes. In the simplest organisms these may be indistinguishable but in the course of evolution one of the gametes becomes larger and filled with stored nutriment: this is called the egg. The other gamete remains small and is frequently motile.

The fusion of the gametes may be imitated by drops consisting of artificial mixtures which come together and unite. Here surface forces are concerned as well as the consistency of the protoplasm. The process recalls the ingestion of bacteria by white blood cells, an operation known as phagocytosis, which assists in protecting the body from invasion by bacteria. It has been suggested that the fusion of gametes in the simplest forms is allied to the process of ingesting food.

The fusion of the gametes is followed sooner or later by the fusion of their nuclei. As far as we can judge this is subject to much the same forces as the fusion of the gametes, but we have no 
direct experimental evidence on this point.

After the fusion of gametes to form the fertilized egg, development proceeds by growth and cell division until an adult organism is produced. One of the important tasks of biology is to explain the mechanism of development. It is possible to control development to a great extent by physical and chemical agencies. It would lead us too far to enumerate the triumphs of this fascinating field of work. It will suffice to mention Loeb's discovery of artificial parthenogenesis by which the egg can be made to develop without fertilization. Usually this involves chemical treatment but in the case of the frog it is sufficient to prick a hole in the membrane which surrounds the egg. The egg then develops, without fertilization, into a normal adult.

By another treatment the egg can be made to begin to develop inside out, with the internal organs on the outside of the body. 
The experimenter is now able to control to an astonishing degree the development of the organism and the future offers great possibilities in this field of work. We should not lose sight, however, of the fact that this sort of development is by no means indispensable to the conception of reproduction. In the simplest forms, such as the blue-green algæ, there is no development in this sense nor is there any fusion of gametes or complicated nuclear division. The organism, which is a single cell without a definite nucleus, simply divides into two and each half is at once a new organism like the original cell. In such a case we need only to explain the mechanism of cell division and growth in order to give a physicochemical explanation of reproduction in its simplest form.

We must remember that reproduction may be entirely absent. Individual cells, as nerve cells, or entire organisms, such as the resting seed, may serve as examples. In these cases there is no reproduc- 
tion, there is no suggestion of nuclear or cell division, yet life may go on for many years.

In view of these facts we must look further for a satisfactory criterion by which living and non-living may be sharply distinguished.

\section{IV \\ MOTION}

A striking feature of many living organisms is their power of motion.

In some cases motion is due to growth. The opening and closing of flowers is due to unequal growth of the inner and outer sides of the petals. When the outside of the petal grows faster than the inside the flower closes; when this relation is reversed it opens. In many cases light and warmth are the determining factors, so that some Alpine flowers may open and close two or three times an hour as clouds pass over the sun. 
Another illustration is afforded by the well known "Praying Palm" of India, which stands before a temple and is revered because its head at evening is bowed as if in prayer, while in the morning it is raised as if to greet the sun. Scientific observation has shown that change of temperature combined with the action of gravitation causes the upper side of the stem to grow more rapidly during the day and the lower side to grow more rapidly during the night, thus causing the daily change of position.

More striking is the kind of motion due to muscular contraction. In biology the word contraction is used in a special sense. When we speak of the contraction of a bar of iron we mean a diminution of volume but when a muscle contracts there is no alteration of volume, but only a change of shape, whereby the muscle grows shorter and thicker. This is also true of the contraction of simple masses of protoplasm, as in the one-celled organisms. In these forms contraction is a much 
simpler phenomenon than in muscle and we therefore have a better prospect of analyzing it and discovering the underlying mechanism.

Motion in these cases and in plant cells may show great diversity. In plants protoplasmic streaming may range from the most irregular sort of motion to a regular flow which passes up one side of the cell and down the other in a continual cycle. In animal cells the type of irregular motion most studied is that found in the ameba, and hence called ameboid. An ameba consists of a single cell which at first sight looks like a structureless mass of protoplasm but is in reality not so simple as it appears. It creeps about by pushing out irregular projections into which part of its substance flows, while other portions of its body are simultaneously retracted. Currents of protoplasm (and corresponding countercurrents) are seen throughout the cell. The interior of the mass is liquid while the exterior is firmer, resembling a jelly. The change 
from liquid to jelly or the reverse apparently takes place with great ease and is a characteristic feature of the creeping movements.

An eminent biologist of the last generation said that it would be futile to seek for any simple explanation of the movements of the ameba. You might as well try, he said, to explain that the movements of a gunny sack with a man inside are due to a very simple mechanism. How far he was wrong may be judged from the fact that it is now possible to imitate the movements of an ameba to a remarkable extent by means of simple mixtures of oil and other substances. Not only does a drop of this kind, which we may call for convenience an artificial ameba, creep about, but its interior, under the proper conditions, shows currents and countercurrents.

We cannot say that we have, as yet, a complete explanation of ameboid motion but we have gone far enough to make it evident that mechanical factors are ade- 
quate to account for the observed phenomena.

A very interesting type of movement is seen in the contractile vacuole, which begins as a tiny drop of clear liquid in the living protoplasm, grows to a definite size and suddenly disappears. The writer has found that precisely the same phenomenon can be produced in artificial cells under proper experimental conditions and this rhythmic process may continue for days.

The movements of living protoplasm appear to depend upon the surface forces which act upon all liquids, as well as on changes in the consistency of the protoplasm. They do not seem to involve anything sufficiently different from motion in non-living systems to be capable of being considered adequate tests of life.

The idea of motion due to contraction is in no way indispensable to the conception of life. A cell which is capable of contraction does not cease to live when it 
comes to rest. In many cells no contraction is ever observed yet there is no question that they are alive. Evidently it is not one of the essential characteristics of living matter.

\section{V}

\section{IRRITABILITY}

LET us now consider irritability as a criterion of life. Irritability is regarded as one of the most fundamental characteristics of living matter, since it enables the organism to adjust itself continually to its environment.

Irritability is often defined as response to a stimulus. Let us see what is meant by this definition.

For the sake of simplicity let us consider a purely physical stimulus, such as a blow. We might compare the effect upon a man with that upon such an object as a billiard ball.

In the first place the response of the 
billiard ball is immediate while that of the man may appear to be delayed. The delay is, however, in appearance only. The blow causes immediate changes not evident to the eye: as the result of these we may get a striking visible phenomenon which we call the response. In reality there has been no delay in the response if we include under this term the entire series of reactions which result from the blow.

In the second place the billiard ball manifests only as much energy as the blow itself imparts while the organism may show in its response very much more. This is because the organism, like a powder magazine, has a considerable amount of stored energy, which can be released by the application of only a little. The tiny spark may have a very small amount of energy as compared to that which it sets free when it falls into the magazine. We see therefore that inequality of stimulus and response is in no way peculiar to living beings. 
After repeated stimulation the organism shows signs of fatigue which disappear after a sufficient period of rest. Similar phenomena are observed in nonliving systems, as in an electric battery which runs down somewhat during activity but recovers on standing. In general such effects are due to temporary exhaustion of the available supply of energy or to the production of an inhibiting substance which gradually disappears during rest.

It is often said that the response of the organism differs from that of an inanimate object, such as a billiard ball, by being advantageous.

It would be absurd to maintain that all the acts of the organism are advantageous. Numerous exceptions will be recalled by all of us. Some actions which seem advantageous on superficial examination may assume a different aspect on more careful study. Putting such cases aside there remain a large number which are regarded by common consent as ad- 
vantageous. Each of these consists of certain processes which take place as the result of the stimulus. In what respect do they differ from the reactions found in non-living matter? With this question in mind let us consider some typical examples of irritability.

One of the striking methods of response is seen in the tropisms. A tropism is a bending or moving toward, away from, or at an angle to the source of the stimulus. A good example is found in the germinating seed. Under the influence of gravitation the stem grows upward, the main root downward, and the side roots grow out at an angle with the vertical.

If sprouting seeds are placed on a wheel which is slowly revolving, the roots are stimulated equally on all sides and consequently do not bend, but if the wheel revolves rapidly, they are stimulated by centrifugal force and grow outward from the center of the wheel. If they are placed at the center of the 
38 THE NATURE OF LIFE

wheel in such a position that the centrifugal force acts on the tip in one direction and on the rest of the root in the opposite direction the root bends as if only the tip were acted on. The stimulus is therefore perceived at the tip and transmitted to the region where the bending takes place. The bending is due merely to the fact that the side of the root which is stimulated grows more slowly than the opposite side.

The root bends under the influence of a variety of stimuli such as light, heat, air, water and various other chemical substances, currents of water, contact, etc. These are all cases of tropism.

The tropisms of plants seem to be susceptible of a physicochemical explanation. Where, for example, a plant bends toward the light it is evident that growth is slower on the illuminated side. As it is well known that light checks growth the explanation seems to be fairly clear. It is, however, complicated by the fact that in many cases the stimulus is perceived at the tip of the plant and the 
bending takes place further back. The stimulus is evidently transmitted to the spot where bending occurs. But while this introduces an additional factor it does not make a physico-chemical explanation impossible.

In some cases no mechanistic explanation of tropism has as yet been reached but since we can predict and control the process we can not doubt that it is completely subject to physicochemical laws. This may be illustrated by the gravitational response of the root. If we place the root on a horizontal wheel we can subject it to a varying amount of centrifugal force by causing the wheel to revolve at different rates. The centrifugal force works horizontally, from the center of the wheel outwards, while that of gravitation works vertically. If the response of the root is wholly subject to physicochemical laws we should be able to determine its direction exactly by varying the forces which act upon it. Since we cannot change the vertical component we 
vary the horizontal one. We find that the direction of growth of the root corresponds exactly to the parallelogram of forces, that is, it obeys the forces acting upon it precisely according to prediction, and in such a manner as to justify the conclusion that it behaves as a machine.

Tropism is also found in animals. Many animals are "the slaves of light": they can not help turning their heads toward the light and, if free to do so, move toward it. In this way we may explain what at first sight seems to be a very complicated case of instinct. Certain caterpillars hatch out in the spring and climb to the top of the branches of trees where they wait until the food appears. This was regarded as a particularly mysterious case of instinct. It was later shown by Loeb, however, that they were forced to climb upward by the irresistible attraction of light. According to his view the response is a tropism and is purely mechanical. 
This illustration serves to show that it is not always easy to distinguish between tropism and instinct. In fact many psychologists believe that tropisms are the basis of instincts and that instincts govern human conduct to a very great degree. According to this view we have a gradually ascending scale from tropism to intelligence with no hard and fast dividing line at any point.

Of especial interest are the movements of simple one-celled animals such as the ameba. If food is placed near them they may approach and try to engulf it by putting out projecting pseudopodia which surround it. This seems a highly advantageous action but the writer has found that it may be imitated by artificial cells which will approach and engulf a variety of materials in the same fashion.

If the ameba comes in contact with a food plant consisting of a filament many times its own length a very extraordinary reaction takes place. The ameba en- 
gulfs a part of the filament which is then softened by digestion and drawn into the body of the ameba. The neighboring portion then suffers the same fate and this process is continued until the whole has been drawn in and neatly coiled up inside the body of the ameba. After digestion has taken place the indigestible skeleton is extruded.

The reaction appears not only advantageous but almost uncanny in its efficiency. It seems to be the last word in advantageous response. Such reactions have led certain biologists to attribute consciousness to these simple animals and to endeavor to analyze their psychic processes. In view of this it is very significant to find that the whole process can be perfectly imitated by non-living materials. A drop of chloroform brought into contact with a delicate glass filament covered with sealing wax ingests the filament just as the ameba ingests the food-plant. It softens the sealing wax, bends the filament and draws it in, coil- 
ing it up neatly inside after the fashion of the ameba. When the sealing wax is all digested the glass skeleton is extruded. The whole process depends upon the familiar forces which act at the surface of all liquids.

Such an experiment suffices to show that we need not despair of finding mechanical explanations for reactions which seem very complex and highly advantageous. In reality we have succeeded in finding such explanations so often that many biologists feel that there is no logical necessity for regarding the simplest cases of irritability as essentially different from certain reactions found in nonliving systems.

Other thinkers have a different attitude. The power of the organism to make continual adjustment between internal and external relations, and the cooperation of its various parts, which we call organization, seem to them beyond our present powers of analysis. Not $i g$ noramus but ignorabimus expresses their 
outlook upon the problems of life. The practical difference between these two schools of thought is perhaps not so great as might at first appear. It is true that the nature of organization and the fitness of the organism for its various tasks seem at first sight to present an overwhelming problem. But this is due in large part to the notion that all organisms possess a mysterious power which fits them for successful existence. But as a matter of fact a goodly proportion of the organisms which have appeared upon the earth have had so little of this fitness that they have perished. Such unfit organisms continually make their appearance but we see little or nothing of them. Among the seeds that we sow are many unfit but they do not grow and we overlook their presence. Given a sufficient variety of forms and the power of natural selection to eliminate all but the fit it does not seem astonishing that the small fraction which survives should present a uniform picture of successful or- 
ganization. In proportion as this point of view prevails the differences between the two schools will tend to disappear. It may be said that the real problem is the origin of the fit. To explain why, among all the possible combinations, some few are able to grow, reproduce, and adjust themselves so as to assure continued existence, may well be beyond our present knowledge. We must perforce wait for more facts before attempting such an explanation. But in the meantime the very search for such facts implies a hope that the explanation will ultimately be reached and this hope is in itself a great incentive to an unremitting search for truth.

\section{VI}

\section{METABOLISM}

LET us now consider metabolism as a test of life. All the chemical activities of the organism are included in metabolism and they are the very essence of 
46

life. The familiar processes of waste and repair in the body illustrate destructive and constructive metabolism.

We shall begin with the green plant, on which all other living things depend for food. Here are joined together the simple substances found in air and water to make the materials which every organism needs for its existence. This is the first step in constructive metabolism. Once these materials (such as sugar, starch, fats, and proteins) have been formed by the green plant they can be used by other organisms to build up their own characteristic compounds.

We may now turn our attention to the activities of the green plant. In the first place it would seem advantageous for it to spread out as much leaf surface as possible, so as to get the maximum amount of air and sunlight. But there is danger that water may evaporate faster from the surface of the leaves than it can be supplied by the root thus causing wilting or even death. We find that 
this is avoided in various ways. Under arid conditions evaporation from the surface of the leaf is often checked by a covering of hairs (giving a gray aspect to desert plants) or by wax, resin or varnish. The leaf surface is often greatly reduced and the stomata, or openings in the surface of the leaf by which water escapes, are fewer in number. In moist and shady situations the opposite tendency is shown: leaves become larger, smoother, thinner and have more stomata.

The arrangement of the leaves on the stem follows a regular order which can be expressed mathematically. This was at first interpreted mystically but is now believed to be due in many cases to mutual pressure of the young leaves at the tip of the stem. This illustrates how theories of development often begin in an atmosphere of mysticism but end with a purely mechanistic explanation.

This arrangement, which often insures a fairly equal exposure of leaves to 
48

the light, is supplemented by a reaction to light which causes partially shaded leaves to push out into the sunshine. This very advantageous reaction seems to be capable of explanation on a physicochemical basis.

A single large tree may expose a leaf surface of more than an acre but the surface which absorbs carbon dioxide from the air is much larger than this. The carbon dioxide enters through the stomata and comes in contact with the green chlorophyll bodies in the cells of the leaf. Within each of these bodies the chlorophyll or green coloring matter is present as very minute particles (almost ultra-microscopic) which offer an exceedingly large surface for absorbing carbon dioxide.

Under the influence of sunlight the carbon dioxide combines with water and oxygen is given off. It is supposed by many investigators that the first compound formed is a substance familiar to us as formalin or formaldehyde. If it 
accumulated it might poison the leaf but it changes to sugar and this in turn may produce starch. It is possible to observe the chlorophyll bodies under the microscope and to see the formation of the starch grains within them.

When starch is burned energy is given off in the form of heat. This energy was furnished by the sunlight and became stored up in the starch. The process of photosynthesis, by which starch is produced from carbon dioxide and water, utilizes the energy of sunlight. It is this which supplies most of the energy needed by animals and plants and which likewise runs our steam engines when wood or coal is burned in them.

The green plant is practically the only place in nature where such storage of energy occurs and it therefore occupies a place of peculiar importance. If we inquire how efficient it is we find that it actually stores less than one per cent of the energy which it receives from the sun. This is due in part to the fact that 
it is unable to make use of all the different kinds of rays found in sunlight. It absorbs principally the red and orange light (as well as ultra-violet). Since it can use only what it can absorb it is to be expected that it will be more active in photosynthesis in red and orange light than in other colors. This seems in general to be the case, as is shown by a very beautiful experiment in which a spectrum is thrown upon a green plant placed in water. Certain motile bacteria which seek oxygen are placed in the water and they gather most thickly around that portion of the plant which lies in the red and orange light, indicating that oxygen is given off most freely there. It should be said, however, that these and other experiments need repeating under conditions which insure that the intensity of all the different rays shall be equal: there is some evidence that in this case the result will be quite different.

From sugar and starch fats may be formed, but to make proteins nitrogen 
must be added. The plant obtains nitrogen from the soil and in some cases from the air. It has been said that the air above each acre of soil contains ten million dollars worth of nitrogen. Many plants of the pea family have tubercles on their roots which contain bacteria capable of taking nitrogen from the air; many kinds of very simple plants living independently in the soil can also fix nitrogen. The attempt has been made to inoculate crop plants such as wheat with organisms capable of fixing atmospheric nitrogen. It has been stated that the wheat plant has this power, independently of the presence of bacteria or other organisms.

Sulphur and phosphorus enter into the composition of some proteins and these substances are often added to the soil. Lime salts are also very necessary and in many cases are used as fertilizers but their function is not clear. Lime. salts have the power of acting as antidotes to the poisonous action of other 
salts and may therefore be said to have a protective action. This applies to animals as well as to plants. The relative proportion of lime salts (as compared with other salts) in blood and sea water is about the same and this is also true of many solutions used for the nutrition of plants. A solution in which the toxic properties of one salt are inhibited by other salts is called a balanced salt solution and such solutions play an important part in biology.

The rôle of mineral substances is not very well understood. The same may be said of the hormones and vitamins which are important for plants as well as for animals.

A hundred years ago it was not believed that any of the food substances or compounds related to them could be produced outside the living cell. But to-day such a feat is a commonplace of chemistry. We are even able to build up such substances as sugar from carbon dioxide and water, in imitation of the plant. 
This can be done in a variety of ways. The source of energy is usually an electric current, radium, or ultra-violet light. Ordinary light can be used in the presence of certain metals such as iron (which also occurs in the plant). By subjecting a mixture of ammonia, carbon dioxide and water, to ultra-violet light nitrogenous compounds can be produced. Some of these appear to be amino-acids from which proteins can be built up.

It may be added that certain bacteria are able by oxidizing compounds of iron or sulphur to gain sufficient energy to utilize the carbon dioxide of the air without the aid of sunlight or chlorophyll. Hence it has been suggested they may have been the precursors of chlorophyllbearing organisms in the process of evolution.

Since many of the most important steps in constructive metabolism have already been imitated in the laboratory it seems probable that others will share 
a similar fate. Rapid progress is being made in this direction and every fresh discovery strengthens the belief that the whole process may be explained by the laws of chemistry.

Let us now consider the processes by which food is utilized to furnish energy. This is known as destructive metabolism and consists largely in the combustion of food in the organism (respiration).

It may be instructive to compare the combustion in the living organism with that in a tallow candle.

The food which enters the body and is stored, or remains undigested for a time, may be compared to the inactive tallow of the candle. If it is to be used it must first be prepared for absorption. As a rule solids cannot be taken into living cells and the food must be liquefied before it can be absorbed. This is accomplished by digestion.

In the candle also the fuel must be liquefied before it can be absorbed. It is then transported to the place where 
it is to be burned. This takes place in the candle, as in the simpler organisms, by such processes as diffusion, capillary action, assisted by convection currents.

When combustion has ceased we find certain substances left over which are given off as gases or as solid particles which constitute the smoke. These may be compared with the excreta of the organism. With a few exceptions, the same substances can be burned in the candle as in the organism. If we introduced into the candle bits of the food substances which can be burned by the organism, they would also be burned in the candle and most of the substances which the organism is unable to burn could not be burned in the candle.

The beginning and the end of the process of combustion is the same in both cases, though the intermediate steps differ. Thus we find that an ounce of tallow ordinarily consumes the same amount of oxygen, sets free the same amount of heat, and produces the same 
amount of water and carbon dioxide, whether fed to a dog, or burned in the candle.

In the candle flame we may point to the spot where the combustion begins and likewise where it ends. The question arises, Can we do the same in the case of the organism? When food is taken into the organism it is transformed into living matter, after a time it again becomes lifeless material. When and how do these transformations take place? We might regard the food as lifeless until it becomes chemically active in the process of combustion. We might also say that when it ceases to be active in this way it again becomes dead material.

If we use this conception as a working hypothesis we can at least give to our ideas a certain degree of precision. It will be seen that this involves the idea that life is a process in which combustion plays a fundamental rôle. This conception of life and of living matter leads us to study it in precisely the same way as 
we study the non-living. We endeavor to discover its underlying mechanism and to bring it under our control.

When we compare the organism to a candle flame, we are struck by certain resemblances. Both are in dynamic equilibrium, that is, they retain their form while continually changing their substance; both carry on processes of combustion which may start with the same substances and end with the same products, and set free the same amounts of energy; both respond to changes in the environment, such as variations in the supply of oxygen or in temperature.

We might go on to point out other resemblances but it will perhaps be more instructive to consider the points of difference. In the first place the combustion of the organism proceeds at a relatively low temperature. This depends upon the fact that it takes place in watery solution: such combustion can easily be imitated in the laboratory. It is greatly facilitated by certain enzymes, 
as is easily shown when we follow the process of combustion or oxidation by means of the changes in color which it sometimes produces. Many plants show changes during the process of death. We are familiar with the blackening which occurs in plants as the result of frost or of injury due to crushing. These changes, which are due to oxidation, are particularly well seen in the common Indian Pipe, whose cells are well adapted for observing the whole process under the microscope. In this case the most rapid oxidation (and consequently blackening) appears to occur in the cell-nucleus. It has been suggested that this may be connected with the fact that the nucleus contains more iron than the rest of the cell.

It is possible to extract from plants and animals colorless substances which if allowed to take up oxygen turn yellow, then red, and finally black. These pigments are responsible for much of the coloration of animals, in skin, feathers, 
and hair, and for many of the autumnal colors of leaves. In the decay of animals and plants in the soil a dark coloration is produced which is due to these pigments.

If an organism is killed by exposure to boiling water the process of combustion ordinarily stops, but if it is killed by certain other methods (as by acetone) the combustion continues after death (in complete absence of bacterial action). The explanation lies in the fact that combustion in organisms depends on enzymes: these are ordinarily destroyed by the heat of boiling water but not by exposure to acetone.

Enzymes play a very highly important rôle in the chemical reactions of the organism. We suppose that the enzyme does not initiate the reaction but merely hastens it. It is often said that its action is analogous to that of oil in lubricating a machine and it need not, theoretically at least, be itself used up in the process. Any substance which acts 
in this way is called a catalyzer. There are catalyzers which hasten oxidation in non-living systems but the term enzyme is reserved for the catalyzers found in organisms.

The importance of enzymes is very great since most life processes are profoundly influenced by them. In view of this we may ask whether they constitute a criterion of life. Cells may be killed in a variety of ways which do not destroy the enzymes and in that case the enzymes may be extracted from the dead cell. In natural death the enzymes continue to work after death and the cell undergoes a process of partial self-digestion known as autolysis.

In some cases the action of enzymes may be imitated by simple inorganic substances, such as colloidal metals.

The special function of oxidizing enzymes (and associated substances) is to activate the inert oxygen of the air and cause it to combine with various substances in the organism. Such enzymes 
are apparently responsible for the oxidation of alcohol to acetic acid in the production of vinegar as well as for changes in color and flavor in the curing of tobacco and tea. They are also active in producing famous Tyrian purple of the Romans, obtained from a shellfish.

The production of light by luminescent animals and plants is due to oxidation carried on by means of oxidizing enzymes. This may be illustrated by an interesting experiment in which the juice of a potato or turnip (which contains oxidizing enzymes) is mixed with pyrogallol (an oxidizable substance) in the presence of hydrogen peroxide, which furnishes oxygen. When this mixture is made in the dark room a distinct luminosity is observed.

While many of the oxidations of the organism can be traced to more or less definite enzymes others have not yet been explained upon this basis. At present we know very little of the various steps in the process whereby food is 
burned but the fact that it stops when the organism is killed by heat indicates that it is due to enzymes.

In many animals the tissues are supplied with oxygen by oxygen carriers in the blood which take up oxygen in the lungs or gills and convey it to the cells. In mammals an iron compound, hemoglobin, performs this office, in the horseshoe crab it is a copper compound; in certain other marine animals compounds of vanadium or manganese. All of these are admirably adapted to the rôle of oxygen carriers and it is remarkable that so many different metals are employed.

The cells of the body are able to take their oxygen from these compounds and hence do not need free oxygen. Many bacteria, protozoa and other organisms get along without free oxygen and to some of them it acts as a poison.

Of late the belief has been gaining ground that living cells can get the oxygen they need by decomposing water. This leaves hydrogen, which may unite 
with free oxygen if it is present or with any of the substances in the organism with which it can combine. If the cell has been stained with methylene blue the hydrogen unites with it forming a colorless compound. This has been proposed as a test of life. It is, however, not certain that it occurs in all living cells and it can easily be imitated by nonliving materials.

There are certain organisms which do not carry the process of respiration to the point of producing carbon dioxide and which therefore differ from the majority of animals and plants.

Plants and animals which require free oxygen quickly show the effects of a deficiency in the oxygen supply. They behave as if anesthetized; but if not kept too long in this condition they recover completely when the normal supply of oxygen is restored. This led Verworn to think that anesthetics produce their effects by depriving the cells of their normal supply of oxygen because they di- 
64 THE NATURE OF LIFE

minish the ability of the cell to absorb oxygen. This would lead to decreased output of carbon dioxide. But this seems to be an error as the experiments carried on in my laboratory have shown that in many cases the anesthetic instead of decreasing the output of carbon dioxide actually increases it.

It has been stated that the combustion of the organism goes on in aqueous solution. This might surprise the lay reader who thinks of his own body as a solid rather than a liquid. He might suppose that it was intended to apply to the blood or other liquids of the body but not to such an apparently solid structure as a muscle. It is, however, in the muscle and other living cells of the body that most of the combustion occurs and this is possible because they combine to an extraordinary degree the properties of liquids with those of solids. In this respect they resemble a jellyfish which is nearly all water yet is so firm that you can not readily squeeze liquid out of it. 
In such a structure substances can diffuse and chemical action can go on as rapidly as in a liquid. Substances which can form structures of this sort are called colloids (from the Greek word meaning glue). A familiar example is gelatin which passes readily from the solid to the liquid state on heating and becomes solid again on cooling. The living substance, however, more closely resembles white of egg which becomes coagulated at higher temperatures and suffers a permanent change. Uncoagulated white of egg can be partly solidified by cooling to a low temperature and completely solidified by partial loss of water: it can be liquefied by reversing the process. Protoplasm seems to pass very readily from the solid to the liquid state and vice versa without change of temperature or loss of water.

In the opinion of some writers protoplasm is comparable to an emulsion such as mayonnaise salad dressing. Such an emulsion can pass under appropriate conditions from a solid state, resembling 
66

butter, to a liquid state resembling cream and vice versa.

There is no evident reason why protoplasm cannot contain at the same time jelly-like materials and emulsions. The question must be left to future investigation. It is, however, perfectly clear that the properties of protoplasm are to a large extent determined by the fact that it is largely composed of colloids, so that some biologists speak of organisms as "colloidal machines." It may be added that it is possible to construct non-living colloidal systems which to a great extent imitate the properties of living matter. Thus protein solutions are affected by heat, heavy metals, and various coagulants in much the same way as protoplasm.

It is evident, therefore, that combustion, as well as other metabolic processes may be regarded as taking place in an aqueous medium.

In conclusion we may emphasize the fact that destructive metabolism oc- 
cupies a peculiar position among life processes. Growth, reproduction, motion and irritability, and constructive metabolism may cease, as in the resting seed, yet life may go on for many years. But when destructive metabolism ceases, life ceases. We can apply this test to the resting seed: as long as it is alive it produces carbon dioxide, when this ceases it is dead.

The cessation of this process is therefore a test of life but we can not say that its continuance is a test for life for we know that when an organism is killed in certain ways it can go on producing carbon dioxide after death.

These facts would seem to indicate that life as manifested in the simplest organisms is a physicochemical process in which destructive metabolism plays a fundamental rôle. This leads us to attempt to control the process. Some very remarkable experiments have been made in this field. It is possible to stop the development of certain organisms 
68

\section{THE NATURE OF LIFE}

at a definite stage and to hold them at this point for a long time; afterward they can be made to finish their development. In experiments on rats it is possible to allow development to proceed on a normal diet and then by substituting a deficient diet to stop development entirely. In this case there is no starvation since the animals do not lose weight. They remain undeveloped and may be kept in this condition long after their brothers and sisters have grown up and had families of their own. If now the normal diet be substituted for the deficient one development proceeds normally.

Thus it is also possible to reverse development and cause certain animals (flat worms) to grow smaller, until they are not as large as when hatched from the egg. During this process they lose some of their organs, returning toward the infantile condition. They can then be caused to develop normally, after which development can again be reversed, and so on. 
We can easily put out the candle and light it again. Can we also stop life processes and then cause them to start up again? When a grain of wheat begins to sprout it shows growth, reproduction of cells by cell division, motion, and the ordinary phenomena of irritability. All these stop if (after 4 or 5 days of growth) the seed be allowed to dry up again. We can easily cause them to start up once more by putting the seed in water. Can we do the same with respect to destructive metabolism, which seems to be a process absolutely essential to life?

If we stop the destructive metabolism of the candle by a violent alteration of its physical structure, as by smashing it with a hammer, we cannot make it burn again in the same way as before. Its fragments may be burned but we shall not get the same candle flame that we had before. In the same way such an organism as a seed may be shattered by a blow and its fragments may go on burn- 
ing for a time but in a somewhat different way. In neither case can we restore precisely the same condition with which we started out.

If we stop the destructive metabolism of the tallow candle by violent chemical action, as by heating it in lye, we shall not be able to relight it any more than we could restore life to an organism treated in the same way.

But if we put out the candle by some means which does not alter its chemical or physical structure, as by cooling it down sufficiently, we shall be able by raising the temperature to make it burn precisely as before. In the same way we might expect that if we cooled down a dry seed to the point where its metabolism stopped, without materially altering its physical or chemical structure, it might be able, when brought back to normal temperature, to resume its activities as before.

As a matter of fact dry seeds have been cooled down to the temperature of liquid 
hydrogen, about $250^{\circ}$ below zero centigrade. At this temperature substances which under ordinary conditions undergo violent reactions with each other do not show any activity when brought into intimate contact. It is a temperature at which all chemical reactions practically cease. If there is any chemical activity in seeds at this temperature it is certainly much less than exists in what we call dead seeds at ordinary temperature. Yet when these cooled seeds are warmed up again and planted in moist soil they grow and develop normally.

We cannot say what would happen if these seeds could be cooled down to $-273^{\circ}$ instead of to $-250^{\circ} \mathrm{C}$. It does not seem probable that this relatively small difference in cooling would prevent them from recovering. At $-273^{\circ} \mathrm{C}$ (absolute zero) all chemical processes would come to a standstill and if we regard life as a physicochemical process we should say that it was extinct.

We are led, therefore, to look upon 
destructive metabolism as a process upon which life depends in a peculiarly intimate way. It sets free in available form the energy necessary to run the living machine. In default of this the machine stops and life ceases. When sufficient food is present the process may go on for a long time, probably in the case of the resting seed for a hundred years, without any constructive metabolism.

This leads us to consider the rôle of constructive metabolism. It is clear that photosynthesis is necessary to store up energy but when this is accomplished by the plant why should further constructive metabolism be needed in the animal in order that its life processes may go on? The constructive metabolism of the animal does not add energy but changes some of the food material in a special and characteristic way. Fats are usually burned without first being changed to a different kind of fat: proteins are transformed. It is a familiar 
fact that a dog fed on mutton breaks down the sheep protein into simpler substances which are in part built up into the proteins characteristic of the dog. Each species of animal or plant apparently has its special kind of protein. This can be demonstrated by injecting into an animal the protein of another species. This is always more or less toxic.

We are inclined to assume that this power of transformation is indispensable to life but it would be interesting to know what would happen if it were taken away. Doubtless the organism would change, but whether all organisms, including the simplest, would die is an open question.

We may sum up by saying that metabolism, once regarded as too mysterious to be understood, now appears to be only a complex chemical process which has been imitated to a remarkable degree. If we can continue the rapid progress of recent years we have reason to hope 
that a satisfactory explanation of its fundamental processes may eventually be reached.

\section{VII \\ SELECTIVE PERMEABILITY}

Another criterion of life which has of late attracted especial attention is the selective permeability of protoplasm. The life of the cell depends on its power to retain certain substances which it manufactures and which are necessary for its existence. These are prevented from diffusing out because the outer surface of the cell is impermeable to them. At the same time this surface allows certain substances to penetrate into the cell from the outside, but excludes others. This is known as selective permeability, and such surfaces are called semipermeable. In some cases, no doubt, a special structure exists at the surface which may be called a semipermeable membrane but the surface itself may behave 
as semipermeable in the absence of any such definite structure.

The fact that the surface excludes certain substances is very important. This may be illustrated by the case of certain fungi which grow on fairly concentrated solutions of copper sulphate. Since copper is poisonous this seems rather remarkable. Analysis shows no copper in the cells of the plant and it therefore seems unable to penetrate.

It is quite possible that hay fever furnishes another illustration. Although the facts are not by any means perfectly clear it seems probable that if the proteins of various kinds of pollen are absorbed by the body the system becomes sensitized to that kind of protein. The case is quite the opposite of immunity where the introduction of a poison renders the body less sensitive. It is well known that each species of animal has its own characteristic protein and that all other proteins act as poisons. Ordinarily when pollen enters the nose or mouth its pro- 
76 THE NATURE OF LIFE

tein is unable to enter the body because the cells of the mucous membrane are impermeable to it. But if they fail to exclude it and a little enters the system, it may become extraordinarily sensitive to further doses so that whenever the pollen comes in contact with the mucous membrane the symptoms of hay fever ensue. The remedy is to avoid contact with the pollen and to try to render the system immune by injecting it in a suitable manner with pollen extract. In case of doubt regarding the kind of pollen which causes the difficulty extracts of various kinds may be applied to a scratch on the skin. When the extract of the irritating pollen is applied a red patch appears on the skin.

Selective permeability makes it possible for two cells in intimate contact to exchange certain materials and yet differ in regard to other constituents and to carry on entirely different kinds of work. Thus deeply colored cells are found next to those which are colorless. If tissue is 
crushed, so that the contents of such cells mingle, new reactions may result. When a bitter almond is crushed, prussic acid is at once evolved: in the normal state the substances which produce this reaction were kept apart by semipermeable membranes. Such membranes may exist within a cell as well as at its surface; if these internal membranes are broken new reactions may start. It is possible that this is what happens in the sense of touch. The contact or pressure may disrupt membranes within the cell and so cause chemical reactions which stimulate the nerves. The stimulus of gravitation which causes the root to grow downward may possibly come under the same category.

When a root which is growing downward is placed in a horizontal position there is a mechanical disturbance of the protoplasm in each cell. A part of the cell contents tends to sink downward toward the bottom of the cell and in so doing may rupture or displace some of 
78 THE NATURE OF LIFE

the delicate membranes in the protoplasm. If this is the case it is easy to see that new reactions may be started which may produce the bending of the root.

In view of what is said above it is not surprising that on cutting or crushing a tissue an increased evolution of carbon dioxide is observed. Since this does not occur in tissues killed by heating it has been called by Tashiro a sign of life. Mr. Davies, working in the writer's laboratory, found that cells killed by acetone continue to give off carbon dioxide after death and that when such dead cells are crushed there is a very marked and immediate increase in the amount of carbon dioxide given off. Hence it would seem that this is not properly to be considered a sign of life.

A similar behavior is to be expected in any non-living system in which mechanical agitation brings into better contact substances which produce carbon dioxide. To what extent this would imitate what 
occurs in the organism we can not definitely say.

As soon as the cell dies, its power of selective absorption disappears. Substances can then diffuse in and out of the protoplasm without hindrance (unless interfered with by the non-living cell wall, as happens in some cases).

It follows that if we can measure the permeability of the cell to various substances, we can tell whether it is alive or dead. One way of doing this is to put the cell into a solution of a dye. Certain dyes will not enter as long as the cell is alive while others enter and become stored up inside, reaching a higher concentration than outside. This process obeys a definite mathematical law as has been shown by Miss Irwin. In the dead cell this storage of the dye does not occur to so great an extent.

Another way is by sending an electric current through the cell; in a salt solution the current is carried by the charged particles derived from the salt 
and if the cell lies in a salt solution the flow of the current will be in proportion to the permeability of the cell to these particles. In the normal condition only a few particles can penetrate and little current passes, but as it dies, the salt enters more and more freely and more current flows through. By measuring the amount of current we can follow the progress of death precisely as we follow the progress of a chemical reaction in a test tube. We then find that death is a very orderly process, following a definite law which can be expressed mathematically. These studies lead us to look upon the death process as one which is always going on, even in a normal, actively growing cell. In other words we regard the death process as a normal part of the life process, producing no disturbance unless unduly accelerated by an injurious agent which upsets the normal balance and so produces death. The activity of the cell need not cease with death but may be merely changed in character. 
SELECTIVE PERMEABILITY 81

An organism injured by exposure to a toxic solution may recover if it is returned to the normal environment before the injury has progressed too far. But if injury has gone beyond a certain point, the recovery may not be complete and the organism may remain in a state intermediate between normal health and a moribund condition.

This is of especial interest, since in physiological literature it seems to be generally assumed that when recovery occurs it is always complete, or practically so, as if it obeyed an "all or none" law. But it is evident that partial recovery may be easily overlooked unless accurate measurements can be made. This fact serves to illustrate the importance of quantitative methods in the study of fundamental problems.

These studies have led to the development of equations which enable us to predict with a satisfactory degree of accuracy the recovery curves which are observed under a great variety of conditions. 
As the result of these investigations we are led to look upon recovery in a somewhat different fashion from that which is customary. While recovery is usually regarded as due to the reversal of the process which produces injury, the conception of the writer is fundamentally different. It assumes that the reactions involved are irreversible (or practically so) and that injury and recovery differ only in the relative speed at which certain processes take place.

The experiments of the writer lead to the view that life depends upon a series of reactions which normally proceed at rates bearing a definite relation to each other. If this is true it is clear that a disturbance of these rate-relations may have a profound effect upon the organism, and may produce such diverse phenomena as stimulation, development, injury, and death. Such a disturbance might be produced by changes of temperature (if the temperature coefficients of the reactions differ) or by chemical 
agents. The same result might be brought about by physical means, especially where structural changes occur which alter the permeability of the plasma membrane at the surface of the protoplasm or of internal structures (such as the nucleus and plastids) in such a way as to bring together substances which do not normally react.

By means of electrical measurements we can follow changes in the cell with sufficient accuracy to enable us to give a mathematical expression to certain fundamental ideas of biology which have never been precisely formulated. Among these are such important conceptions as vitality, injury, recovery, and death. A mathematical theory of the mechanism of injury and recovery has likewise been developed by the writer.

We find that some aquatic organisms are killed when placed in a solution of common salt, but that death can be hindered by the addition of a lime salt. We speak of this as antagonism between 


\section{THE NATURE OF LIFE}

the two substances. The rate of death depends on the amount of lime salt added and the death curve can be predicted by means of the mathematical formulæ already mentioned. We can also predict the recovery curves obtained when the organism is transferred from any of these solutions to its normal environment.

In conclusion we may say that in many respects the selective action of the protoplasm can be imitated but in others it cannot. The subject is peculiarly difficult because as yet we know very little about the rates at which various substances penetrate. But with improved technique we may hope to get a clear picture of the whole process and to interpret it in the light of physics and chemistry.

\section{VIII}

\section{ELECTRICAL FORCES}

ThE electrical experiments just described lead naturally to a consideration of certain other electrical tests. 
In the first place it is observed that injury changes the electrical condition of the cell. If injured and uninjured cells are connected to a galvanometer by unpolarizable electrodes a current flows through the galvanometer from the normal to the injured cells.

It would seem at first sight that this might serve to distinguish a dead cell from a living one. We find, however, that in many cases the curren" ("current of injury") which may be very noticeable when the cell is first injured gradually falls off and disappears after the cell is entirely dead. We also find that in tissues, such as muscle, which can be easily excited to activity the behavior of active cells (as compared with one in the resting state) with respect to the current is very much like that of an injured cell. The current therefore seems to be due to a disturbance in the cell, produced by stimulation or by injury, rather than to death. In order to use it as a test of life we must injure or stimulate a part of the 
organism and compare its electrical condition with a normal or an unstimulated portion.

It is well known that activity and injury are commonly accompanied by an increased production of carbon dioxide and in view of this it is not surprising that electrical changes should occur. In any case we shall probably not go far wrong in thinking that a study of the chemical changes will give us the key to the explanation of the electrical phenomena.

Certain other electrical manifestations of living matter are apparently of universal occurrence as, for example, the fact that if an organism be brought into contact with a salt solution at one point and with a more concentrated one at another point the latter is electrically negative with reference to the other. This, however, can be easily imitated with nonliving materials.

If an organism is connected to a galvanometer by unpolarizable electrodes 
and an induction shock is sent through it we observe that immediately afterward a current (called a "blaze current") flows through the galvanometer, sometimes in the direction of the induction shock, sometimes in the opposite direction. No such current is observed when a dead organism is used. Waller, who discovered this phenomenon, calls it a test of life. He states, however, that as a rule he was unable to obtain it in marine algæ. This may be due to the fact that the sea water interferes with the manifestation of the current by producing a kind of short circuit, but this seems improbable because this would abolish all electrical effects and this is not found to be the case. Moreover other cells such as frogs' eggs sometimes fail to give it. In any case the fact that the blaze current is not found in all organisms makes it less satisfactory as a test of life. 


\section{IX}

\section{THE CONTROL OF LIFE}

What shall we conclude from our survey of the tests of life? Certain of them can be imitated to a remarkable degree and seem to be reducible to mechanism. In other cases we have not yet reached this stage but we are making continual progress toward a physicochemical explanation, so that many investigators are convinced that such an explanation must eventually be reached.

It is certainly true that all biologists agree that the organism is in some respects a machine but to what extent it is a machine, is still a matter of controversy. Some who think that the higher organisms cannot be reduced to mechanism feel no hesitation in regarding the simplest forms of life as pure machines. Such organisms are, however, sufficiently complex to challenge our best powers of analysis. While we can imitate more or 
less successfully the various life processes taken one at a time no one has made an artificial cell which can imitate all these life processes simultaneously. It is evident that the simplest living cell is a machine of great complexity. This is only another way of saying that we have a great many factors, or variables, to deal with. If we can measure each of these we may hope to arrive at a clear picture of the life processes of a cell and to express them in a definite manner, preferably in mathematical form. If we can do this we may also hope to predict the course of life processes as we predict the course of the tides, which also involves a great many variables. We need not despair of the power of the human mind to deal with such a large number of variables providing each of them can be measured.

Our task then is clearly defined. It is to measure each of the factors or variables which determine life processes to the end that we may imitate, predict 
and control the activities of the organism.

When we have done this successfully we shall doubtless be able to say whether the simplest cells possess any features which cannot be explained upon a physicochemical basis.

In the meantime we are free to form such working hypotheses as we choose. It should be said, however, that the mechanistic point of view has been vastly more productive in research than the vitalistic. If we regard the organism as a machine we have a powerful incentive to endeavor to control it as we control other machines.

The imitation of various life processes has already been discussed. It has also been stated that in many cases the behavior of the organism is predictable, as in the reaction of the root to gravitation or in the changes of the electrical resistance of the organism under various conditions. If we deal with large numbers of individuals (as the chemist and physicist deal 
with large numbers of molecules) their average behavior can be predicted in certain respects with surprising accuracy. This sort of prediction depends on the use of statistical methods which are becoming very useful in biology.

Let us now turn to another subject which is destined to play a prominent rôle in biological progress, namely, the control of life-processes.

We have already learned to control the development and behavior of organisms to such a remarkable degree that it would be difficult to set any limit to what we may hope to accomplish.

Every one is aware, for example, of the way in which the development of the human body is controlled by the thyroid gland. If it fails to function properly the individual may develop into a cretin, that is, a dwarf with a peculiar cast of countenance, a dry and parchment-like skin, defective in mind or even idiotic. Transplantation of a thyroid gland into various parts of the body in childhood 
makes a great improvement. Feeding thyroid gland also helps but is less effective than transplantation.

Lack of thyroid activity lowers the whole metabolism, excessive activity of the thyroid has the opposite effect. The mind instead of being sluggish is overactive, often excitable and troubled by anxious fear, the eyes may protrude, the body tends to be taller than normal. In short the symptoms are quite the opposite of those found when the thyroid is subnormal.

To what extent the effect of the thyroid depends upon its content of iodine is not yet wholly clear. We know that both thyroid tissue and iodine have a remarkable effect on development in certain animals. Feeding thyroid to tadpoles causes them to develop rapidly into frogs; on the other hand feeding thymus delays metamorphosis and the tadpoles become gigantic in size. Feeding iodine in the form of inorganic salts or free iodine has less effect than feeding thyroid. 
Another ductless gland which has a marked influence on development is the hypophysis, or pituitary gland, situated in the brain. If its activity is less than normal in childhood the body becomes abnormally fat; if its activity is above normal the body becomes abnormally tall and slender and under some conditions there is abnormal enlargement of the hands and feet and alteration of the face by thickening the skin and connective tissue. This may be accompanied by a lessened mental activity. The removal of the hypophysis from a young animal profoundly affects the development. The animal grows but little, and development comes nearly to a standstill, but it continues to live in this condition.

The experiments of Steinach on young rats show the effect of glands in the most striking manner. He succeeded in transplanting testes from the male into the female and ovaries from the female into the male. This exchange of organs produced remarkable results. The males 
which had received ovaries in place of testes took on the characters of the female, including the more graceful form, softer fur, larger nipples and even the habits of the female. The breasts secreted milk and these animals suckled young.

The females which received testes in place of ovaries showed less effect but acquired to a considerable extent the heavier build, larger head, coarser fur and the habits of the male.

In all these cases the gland produces a small amount of substance, called a hormone, which influences development. There are doubtless a large number of such hormones. Their influence on bodily form and on mental states is just beginning to be more fully appreciated. Doubtless the immediate future will witness rapid advances in this field of study. The question arises whether we can introduce hormones, or artificial substitutes for them, into the body and so influence development. There seems to be 
no reason to think that this cannot be done. Herrmann succeeded in extracting a hormone from the corpus luteum of the female guinea pig which on injection stimulated the development of the female characters. The nature of this material is unknown except that it appears to be a lipoid (fatlike) substance but it is, of course, possible that the active substance is quite different and is merely associated with the lipoid.

The hormone produced by the suprarenal capsules, called adrenalin, has not only been isolated but thoroughly studied. Its chemical structure is known and it has been made artificially. It has an extraordinary effect upon muscle and hence upon the blood vessels, so that it can be used in certain surgical operations (removal of teeth or tonsils) to prevent excessive bleeding. The injection of .00000000125 gram of adrenalin into a frog has a perceptible effect on the rate of bleeding. Cannon states that in higher animals it may be poured out into 
the blood stream as the result of anger, thereby increasing the muscular tonus. It affects also the nervous system and other organs.

The fact that the injection or feeding of hormones has such marked effects leads us to ask whether other substances can be used in the same way. As a matter of fact a great variety of substances can be used to influence development. We may mention the fact that when plant lice are placed upon rose twigs whose lower ends dip into water the development of the insect may be easily determined by substances added to the water. Thus a variety of salts can be added to the water which insure that the plant lice acquire wings; but if alcohol is added to the water they remain wingless.

Stockard, and later McClendon, found that by adding alcohol and other substances to the sea water the developing fish produced cyclopean eyes, that is, the two eyes were fused into one. 
In the remarkable experiments of Loeb it was found that merely treating unfertilized sea urchin eggs for a short time with butyric acid, followed by somewhat concentrated sea water, caused them to develop just as if fertilized by sperm.

Loeb also found that by adding a small amount of alkali to the sea water he could cause the sperm of the starfish to enter the egg of the sea urchin and thus produce a hybrid which does not occur in nature.

We may recall some of the effects of special kinds of food. It is well known that bees create a queen by feeding with a spe zial substance called "royal jelly." The other females which do not receive this food become the sterile "workers." A very interesting experiment was made by Marchal upon certain wasps. The workers or sterile females attend to the feeding of the larvæ. Marchal took away the larvæ but continued to provide the workers with food. As there were no larvæ to feed they ate it themselves and as 
a result their ovaries began to develop and they were able to lay eggs. In this connection it may be recalled that Evans has recently announced the discovery of "vitamin $\mathrm{X}$ " which is necessary for fertility. Rats were given a diet (casein, lard, and cornstarch) on which they grew and developed in a normal manner but in some cases they were completely sterile. The sterility could be cured by the addition of certain substances to the diet, such as lettuce, alfalfa, wheat germs, milk fat, or meat.

Vitamin $\mathrm{X}$ is distinct from the other well known vitamins, such as the fat soluble A and the water soluble B and C, which are necessary for growth and health. Very little is known of their nature, but another, vitamin D (formerly called bios), which is needed for the growth of yeast has recently been obtained in crystalline form and we may hope to learn its chemical structure.

A great many cases are known where, as in the case of vitamins, small amounts 
of substances promote growth to an astonishing degree. Thus peat, inoculated with certain bacteria produces substances which greatly stimulate the growth of crops.

Certain marine organisms will not grow in artificial sea water until a few drops of natural sea water are added. The growth of certain fungi is greatly increased by minute amounts of certain metals.

In all these cases the growth-promoting substance acts at a very low concentration: often a mere trace suffices. In the future we shall be compelled to pay more attention to substances which act at great dilution.

The form of the plant may be controlled in a great variety of ways. One of the most potent substances for influencing development is water. This is illustrated by the behavior of a potato lying on a dry table-top without food or water. Under these circumstances a potato can grow for a long time. It de- 


\section{THE NATURE OF LIFE}

velops into something which superficially resembles a cactus far more than a potato. The stem is very short and thick, with nodes close together, the leaves are reduced to small growths resembling spines, and the whole aspect is that of a desert plant. A photograph of such a plant might easily be mistaken for that of a cactus, even by botanists.

In some aquatic plants the form of the leaf is determined by their position with reference to the water. For example the Mermaid Weed (Proserpinaca) produces under water a leaf which is composed of fine threadlike parts arranged on each side of a central rib. Above the water the same plant produces a flat elongated leaf resembling that of land plants. By growing the plants in an aquarium and alternately lowering and raising the water level the plant can be made to produce each type alternately.

Light produces remarkable effects upon plants. Not only does it cause the upper and lower sides of the leaf to differ 


\section{THE CONTROL OF LIFE 101}

but it largely determines the position assumed by the leaf and in many cases modifies its external form. Thus the harebell (Campanula) produces leaves of a very different shape on a branch which is covered so as to exclude light. The water hyacinth (Eichornia) loses in the shade to a considerable extent the remarkable swollen leaf stalk filled with air which assists the plant to float on the surface of the water.

Light modifies the color and the fragrance of flowers, as well as of other parts of the plant. Reducing the amount of light by shading plants for a part of each day causes some species to produce flowers and fruit very much earlier, while in other cases the reverse occurs, as shown by the experiments of Garner and Allard.

Marked modifications are produced in some cases by temperature. Every one has noticed the manner in which plants at high altitudes hug the ground, in many cases forming rosettes which spread out 
102 THE NATURE OF LIFE

as close to the surface as possible. In the lowland the same plants grow upright and have a very different aspect. Experiment shows that by placing the plants on ice every night in the lowland they can be made to assume the curious aspect of the alpine situation.

Very striking effects are observed in insects. By exposing butterflies in the chrysalis stage to high or low temperatures we are able to change their colors in a remarkable manner: the same species treated in this manner may produce various forms which occur in nature and were at one time regarded as different species.

Stockard has found that when developing trout are cooled at certain stages of development all degrees of doubling are observed. In some cases the fish has two heads, in others two tails, or the body may be double throughout.

A doubling may also be produced by simple physical means in the case of certain eggs. Loeb was able to produce 
Siamese twins in sea urchins by causing the egg to extrude a part of its contents and so that there were two portions united by a bridge of protoplasm. In many cases each portion developed, forming two individuals connected by a ligature. In the same way triplets could be produced.

It would seem needless to multiply instances, for these few examples suffice to show that the experimenter has power to control development to a remarkable degree. We may, however, inquire to what extent the modifications produced by the experimenter are hereditary.

It is often stated that simple one-celled organisms, such as bacteria, can be modified by treatment so that they and their descendants are noticeably altered. Thus it is a common practice to decrease the virulence of bacteria so that they may be used for various purposes. We must bear in mind, however, that the culture may contain different strains and that the treatment may do nothing more 
than inhibit the multiplication of a virulent strain and allow a less virulent one to develop.

The case is quite different when a cell takes on new characters as the result of treatment and its descendants retain these characters. In this connection we may mention the remarkable results obtained in the artificial production of cancer.

Yamagiwa and Ichikawa produced cancer by painting the ears of rabbits with coal tar. They were led to this experiment by the well-known fact that chimney sweeps and tar workers are particularly subject to cancer. The effect of the tar is to stimulate normal cells into an abnormal growth and multiplication. This continues in the descendants of these cells since they continue to produce cancerous tissue and in the case of white mice Deelman was able to transplant such cancers to a normal animal where the cancer continued to grow. This cancer was then again transplanted to a nor- 
mal animal with the same result and so on until the original cancer had been transplanted eleven times in succession.

Much more efficient than crude tar is the distillate which comes off when tar is heated to over $300^{\circ} \mathrm{C}$. An ether extract is also efficacious and likewise a watery extract of soot which has been mixed with lime.

The question arises whether it is possible to affect the germ cell so that it will take on new characteristics which will be shown by its descendants. There is considerable evidence that this is the case. When alcohol is given to chickens or guinea pigs, as in the experiments of Pearl and Stockard it affects the germ cells so that the characters of the offspring are altered and this persists for two or more generations. In the case of guinea pigs the offspring of parents treated with alcohol are less vigorous and have a high death rate. Their eyes show abnormalities and they are in other ways defective. It would appear that 
106 THE NATURE OF LIFE

the weaker germ cells are injured or killed by the alcohol. The stronger are uninjured or may possibly be stimulated. In any case there is a rapid elimination of the weaker and in the fourth generation a superior strain results. It should be understood that the alcohol is applied to the parents of the first generation only, the four subsequent generations receiving no alcohol. In the experiments of Pearl on chickens this improvement occurred much more rapidly.

A more permanent effect was obtained by Guyer by introducing material from the eye of the rabbit into fowls where it caused the production of a substance which was injected into the rabbit and caused the offspring of the latter to have defective eyes. It is well known that the introduction of foreign protein causes the body to produce substances which tend to destroy or precipitate that protein and it is possible that a body of this sort is responsible for the effects obtained. If the fowl produced a sub- 
stance which attacks the protein of the rabbit's eye it would be natural to expect that the injection of this substance into the rabbit would produce defective eyes. The case is not quite clear, however, since it appears that many poisons affect the eye more quickly than other parts.

Guyer states that the effect of a single treatment has persisted for nine generations and that there is no reason to suppose that it will not go on indefinitely since the imperfections of the eye tend to become worse in succeeding generations and also to occur in a proportionally greater number of young. It seems possible that the material from the defective eye of any individual may get into the circulation of that individual and cause the production there of substances which are destructive to the protein of the eye; if these substances pass into the developing young they might produce defects of the eye.

In these cases the poisonous agent 


\section{THE NATURE OF LIFE}

probably acts directly upon the germ cell. We are particularly interested in knowing whether it is possible to produce inherited effects indirectly by inducing changes in the body cells which then react in such a way as to alter the germ cell. If this were possible we might expect that the normal activity of the body cells might also affect the germ cells and that in this way the inheritance of so-called acquired characters could be brought about.

We are not yet able to answer this question decisively. Some recent experiments of Griffith, Bentley and Detlefsen are of interest in this connection. White rats were kept for several months in cages which revolved continuously at a rate of 60,90 or 120 revolutions per minute. Such rats when returned to normal conditions showed disturbances of the equilibrating apparatus as evidenced by modified muscular and ocular movements and twisting of the head and neck. These disturbances are inherited and it would 
therefore appear that an effect upon the body cells can be transmitted to the germ cells. But it is too soon to draw any farreaching conclusions from this series of experiments, especially as disturbances of equilibrium sometimes appear in rats which have not been subjected to treatment. We must be the more cautious in this regard as a great many experimenters have vainly sought to prove the inheritance of acquired characters and have reached the conclusion that such inheritance is extremely doubtful.

One of the most important problems of biology is to discover how changes are produced in the germ cells. One way of attacking this is to observe under what conditions spontaneous changes occur in germ cells which produce the so-called mutations. Such mutations are now accessible to observation in considerable numbers. Over three hundred of them have been observed by Morgan and his co-workers in the fruit fly (Drosophila). These embrace the most diverse features, 
including changes in eye-color, shape of wings and body, hairiness, and partial or complete loss of organs.

In order to control these mutations we must discover the physicochemical factors on which they depend. If such control can be established we shall be able to create new species. The aim of modern biology is to accomplish this, just as we control growth, metabolism, irritability, and other life processes.

Upon man's control of nature rests all our civilization. The last and most difficult step in the conquest of nature is the control of life. This offers so much promise that no effort is too great to consecrate to it, and each step forward is of fundamental importance for human welfare. 


\section{INDEX}





\section{INDEX}

Absorption, 54

Acetic acid, 61

Acetone, 59

Acquired characters, 108,

109

Adrenalin, 95

Air, 38, 51

Alcohol, 61, 96, 105, 106

Ameba, 31, 32, 41, 42, 43

Amino-acids, 53

Anesthetics, 63, 64

Antagonism, 52, 83

Arrhenius, 5, 6, 7

Artificial cell, 16, 17, 18,

$19,20,23,33$

Artificial parthenogenesis, 27

Assimilation of food, 9, 11,

15

Autolysis, 60

Autumnal colors, 59

Bacteria, 6, 11, 26, 50, 51, $53,62,99$

Balanced solution, 52

Bentley, 108

Bitter almonds, $\mathbf{7 7}$

Blaze current, 87

Blood, 52, 62, 64
Blue-green algæ, 28

Butterflies, 102

Butyric acid, 97
Campanula, 101

Cancer, 104

Candle, 55, 56, 57, 69, 70

Cannon, 93

Capillary action, 55

Carbon dioxide, 12, 48, 49, $52,53,56,63,64,67,78$, 86

Catalyzer, 60

Caterpillars, 40

Cell division, 9, 10, 12, 15, 24, 29

Cellulose wall, 14

Centrifugal force, 37

Change of form or color, 15

Chemical activities, 45

Chemical stimuli, 38

Chloroform, 42

Chlorophyll, 48, 49, 53

Coal tar, 104

Colloids, 65

Collodial metals, 60

Coloration, 58, 59

Combustion, 55, 56, 57, 59 ,

$61,63,64,66,69,70,72$ 
Consciousness, 42

Constructive metabolism, $53,67,72$

Contractile vacuoles, 33

Contraction, 30, 33

Contact, 38

Control of life, 21, 67ff., $88 f f$.

Copper, 17, 62

Copper sulphate, 75

Corpus luteum, 95

\section{Cretin, 91}

Crushing, 58

Current of injury, 85

Davies, 78

Death $58,59,67,80,82,83$

Deelman, 104

Detlefsen, 108

Destructive metabolism, $54,67,69,70,72$

Development, 27, 28, 68, 82

Development, reversal of, Fungi, 75, 99 68

Differentiation, 9, 11, 12, 15

Diffusion, 55

Digestion, 54

Drosophila, 109

Dyes, 79

Dynamic equilibrium, 57

Egg, 26, 27
Eichornia, 101

Electric current, 53

Electrical forces, 84ff.

Emulsion, 65

Energy, 35, 36, 57

Enzymes, 57, 59, 60, 61, 62,79

Evaporation, 47

Excreta, 55

Eye, 106, 107

\section{Fatigue, 36}

Fats, 46, 50, 72

Feathers, 58

Fertilizers, 51

Filterable viruses, 5

Fish, 96

Formaldehyde, 48

Formalin, 48

Food, 56

Fowls, 106

Frost, 58

Fruit fly, 109

Gamete, 26

Garner and Allard, 101

Gelatin, 17, 65

Germ cells, 105

Gills, 62

Gravitation, 30, 37, 39, 77

Griffith, 108

Growth, 8ff., 29, 67, 99 
Guinea pig, 95, 105

Guyer, 106

Hair, 59

Harebell, 101

Hay fever, 75, 76

Heat, $38,55,66$

Heavy metals, 66

Hemoglobin, 62

Herrmann, 95

Hormones, 52,

Hydrogen, 3, 62, 63, 70

Hydrogen peroxide, 61

Hypophysis, 93 96

Leaf, $47,48,59$

Light, 38, 40, 48, 61, 100, 101

Lime, 51, 52, 83, 84, 105

Loeb, 27, 40, 97, 102

Lucretius, 4

Luminescent animals, 61

Lungs, 62

Manganese, 62

Marchal, 97

McClendon, 96

Membrane, 14, 16, 17, 18, 77, 78

Mermaid Weed, 100

Methylene blue, 63

Imbibition, 13, 15, 16, Mice, 104 20

Mineral substances, 52

Imitations of life phenomena, 21,89

Immunity, 75

Indian Pipe, 58

Injury, $81,82,83,86$

Injury, current of death, Natural selection, 44 85

Intelligence, 41

Iodine, 92

Iron, 53,58

Irritability, 67

Irwin, 79

Jelly fish, 64

Kidney bean, 11
Morgan, 109

Motion, 29ff.

Muscle, 31, 64

Mutations, 109, 110

Nerve cell, 10, 28

Nitrogen, 50, 51, 53

Nuclear division, 10, 25, 28, 29

Nucleus, 58, 83

Organic acids, 18

Osmosis, 13, 15, 16, 20

Ovaries, 93, 94

Oxidation, 58, 60, 61 
Oxygen, 50, 55, 57, 60, 61, Protozoa, 62 $62,63,64$

Oxygen carriers, 62

Pseudopodia, 41

Prussic acid, 77

Pyrogallol, 61

Pasteur, 4

Pea family, 31

Rabbit, 106

Pearl, 106

Radium, 53

Pearl, 105

Rats, 68, 93, 98, 108

Peat, 99

Permeability, 74ff.

Recovery, 82, 81, 83

Phagocytosis, 26

Phosphorus, 51

Photosynthesis, 40, 50, 72

Pigments, 58, 59

Regeneration, 24

Repair, 46

Reproduction, 22ff., 24, 67

Respiration, 54, 63

Rhythmic process, 33

Pituitary gland, 93

Plant lice, 96

Root, $37,38,39,40,51,77$

Plastids, 83

Pollen, 75, 76

Rose, 96

Royal jelly, 97

Potato, 61, 99

Salts, 18

Potassium ferrocyanide, Sealing wax, 42

17

Praying Palm, 30

Prediction of life phenomena, 21

Prediction of life processes, 89

Proserpinaca, 100

Proteins, 18, 46, 50, 51, $53,66,72,73,75,107$

Protoplasm, 65

Protoplasmic membrane, 14, 17, 23

Protoplasmic

31
Sea urchin, 97, 103

Sea water, 52, 99

Seeds, 11, 20, 28, 37, 67,

$69,70,71,72$

Selective permeability, $74 \mathrm{ff}$.

Semi-permeable

mem-

brane, $74 \mathrm{ff}$.

Sexual reproduction, 25

Siamese twins, 103

Skin, 58

Soil, 51, 59

streaming, Soot, 105

Spontaneous generation, 4 
Spores, 6, 7

Starch, 46, 49, 50

Starvation, 68

Stem, 37

Steinach, 93

Stimulation, 82, 85, 86

Stimulus, 34, 35, 38, transmission of, 39

Stockard, 96, 102, 105

Stomata, 47

Strawberry, 23

Sugars, 18, 46

Sulphur, 51, 53

Sunlight, 49, 50, 53

Surface forces, 26, 33, 43

Tannic acid, 17

Tashiro, 78

Temperature, 18, 30, 57, $65,70,71,82,101,102$

Testes, 93, 94

Thyroid, 91, 92

Toxicity, 81

Tropisms, 37, 38, 39, 40,41
Turnips, 61

Tyndall, 4

Tyrian purple, 61

Ultra-violet light, 53
Vanadium, 62

Verworn, 63

Vitality, 83

Vitamines, 52, 98

Waller, 87

Wasps, 97

Water, 38, 99; absorption of, 3,161

Water glass, 17

Water hyacinth, 101

Wheat, 69

White blood cells, 26

Willow, 24

Yamagiwa, 104

Yeast, 95 







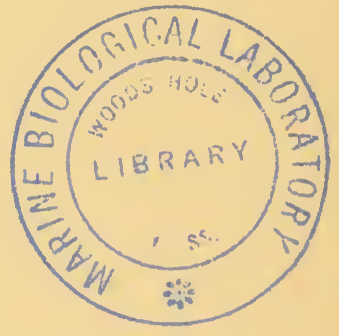


